\title{
LA EXCLUSIÓN DEL INMIGRANTE DEL PROCESO DE DETERMINACIÓN DE SUS DERECHOS
}

\section{THE EXCLUSION OF IMMIGRANT FROM THE PROCESS OF DETERMINING HIS RIGHTS}

\section{Emilia M. ${ }^{a}$ Santana Ramos ${ }^{1}$}

\section{Resumen}

La positivación jurídica de la dignidad personal y del libre desarrollo de la personalidad no puede hacer excepción de la condición del individuo, con independencia de su estatus de nacional o extranjero. No cabe, en este sentido, ningún tipo de discriminación en relación a la adquisición por el inmigrante de derechos inalienables del ser humano. La existencia de un deber de igual trato, genera un punto de referencia que ha de ser respetado por cuantos tengan el poder o la capacidad de incumplirlo.

Ese punto de referencia inmediato para la efectiva garantía de los derechos que deben asistir a los inmigrantes en el país de acogida, no es otro que el respeto por la dignidad personal con independencia del lugar en el que se encuentre el individuo.

En este sentido, la aplicación indiscriminada del esquema normativo del libre desarrollo de la personalidad y el efectivo respeto a la dignidad de la persona, constituye una inequívoca exigencia constitucional, que ha de hacerse realidad en el trato que las autoridades estatales den a los inmigrantes que acceden a su país, sea esta entrada denominada legítima, legal o ilegal.

Palabras clave: Discriminación, inmigrante, diversidad, derechos humanos, identidad cultural.

\begin{abstract}
The legal positivation of personal dignity and the free development of personality cannot make exception of the condition of the individual, derived from his status as a national or a foreigner. There is no, in this sense, any kind of discrimination in relation to the acquisition by the immigrant of inalienable rights of the human being.

Because, the existence of a duty of equal treatment, generates a point of reference that must be respected by those who have the power or the ability to default.

This immediate reference point for the effective guarantee of the rights to be assisted by immigrants in the host country is no other than respect for personal dignity irrespective of where the individual is located.

In this sense, the indiscriminate application of the normative scheme of the free development of personality and the effective respect for the dignity of the person, it is an unmistakable constitutional requirement, which has to be realized in the treatment that the state authorities give to the immigrants who accede to their country, is this entry called lawful, legal or illegal.
\end{abstract}

Keywords: Discrimination, immigration, diversity, human rights, identity cultural.

\footnotetext{
${ }^{1}$ Profesora Doctora del Área de Filosofía del Derecho. Facultad de Ciencias Jurídicas. Universidad de Las Palmas de Gran Canaria (España). E-mail: esantana@dcjb.ulpgc.es.
} 


\section{INTRODUCCIÓN}

Las sociedades modernas vienen caracterizadas fundamentalmente por la diversidad de grupos culturales que coexisten en un mismo territorio. Afirma en este sentido, Souto Galván $(2014,9)$, que la diversidad cultural presente en la sociedad occidental actual, es un hecho que conlleva manifestaciones de índole social, económica, jurídica, etc. Derivado de ello, la inclusión de culturas, etnias y religiones distintas de aquellas que tradicionalmente se han aposentado en Europa ha desvelado un debate todavía no clausurado que plantea cuestiones diversas (...). (Souto, 2014, 9). Por lo cual, no podemos olvidar que muchos de esos grupos sociales se encuentran en una situación minoritaria respecto al grupo mayoritario que domina, y por ende, tiene mayor incidencia en la construcción de la identidad del contexto social y cultural en ese territorio común, provocándose situaciones indeseables de discriminación y exclusión.

Desde ese enfoque, las identidades colectivas, sean de tipo cultural, nacional o religioso siguen generando un importante rechazo por parte de quiénes, pues la perspectiva liberal más tradicional, atribuye a las mismas su incapacidad para permitir la generalización de los derechos (Del Real, 2005, 177), propugnando fórmulas que impiden reconocer y proteger los mismos derechos fundamentales a todos los hombres frente a las intromisiones por parte del Estado o de los demás individuos, en garantía de una libertad de elección muy amplia, permitiendo adoptar a cada uno su propia concepción de la vida (Ruiz, 2005, 41).

La protección de los intereses de las minorías culturales se articula, por tanto, desde esta vía, mediante el reconocimiento de derechos colectivos. "En este sentido, se deduce que quienes se proclaman partidarios del reconocimiento de los mismos, suelen aducir que determinados grupos tienen una identidad claramente definida y capacidad para la agencia moral efectiva. Por tanto, del mismo modo que a las personas se les dota de unos derechos individuales para la protección de ciertos bienes valiosos que les son inherentes, cuya salvaguarda justifica la imposición de una serie de deberes a los demás, también los grupos o minorías poseen unos intereses legítimos, tales como la autonomía política, la preservación cultural o el mantenimiento de la identidad, que han de ser preservados. Pero a diferencia de los derechos individuales, el titular de los derechos colectivos ha de ser necesariamente el grupo y no sus miembros individualmente considerados, pues hay ciertos bienes que únicamente los grupos pueden poseer" (Ruiz, 2005, 57-58). Es por ello, que resulta necesario el establecimiento de políticas públicas adecuadas que avalen con eficiencia las garantías 
necesarias en aras de alcanzar una inserción real de las poblaciones que puedan sufrir riesgo de exclusión.

En la actualidad, la inmigración plantea cuestiones importantes en torno al desarrollo humano, el reconocimiento de los derechos humanos como derechos universales, la convivencia pacífica, la ciudadanía multicultural, entre otros.

La mayoría de las sociedades actuales están formadas por grupos identitarios pertenecientes a culturas y valores diferentes. Esta situación, hace que los grupos minoritarios se encuentren en una posición más desfavorecida frente al grupo de la cultura dominante. En este sentido, los procesos de inclusión por parte de las políticas públicas y de los actores sociales, deben actuar con eficiencia para alcanzar soluciones al problema de desigualdad manifiesta.

Como ha puesto de manifiesto M. Carbonell $(2003,853)$, el problema fundamental en el reconocimiento de los derechos colectivos es la dificultad que genera la determinación de los sujetos y de los objetos que se han de ser preservados: “¿qué es una cultura?, ¿qué son los derechos colectivos?, ¿cómo distinguir, dentro de las sociedades pluralistas del presente, los grupos relevantes para la asignación de estatus jurídicos diferenciados?".

El discurso sobre la identidad cultural y la importancia que cobra en ámbitos sociales y políticos no resulta reciente, sin embargo, en la actualidad y como reconoce Bauman $(2011,16)$, "la identidad se ha convertido ahora en un prisma a través del cual se descubren, comprenden y examinan todos los demás aspectos de interés de la vida contemporánea"

La importancia de las culturas, la identidad de un pueblo o nación, asume un valor indiscutible en la determinación de los derechos individuales, sobre todo, amparándonos en la idea de la universalidad en la que se presumen coexisten los derechos culturales.

Así viene entendido por la Declaración Universal de los Derechos Humanos, cuando defiende en su artículo 22 donde reza que toda persona, como miembro de la sociedad, tiene derecho a la satisfacción de los derechos económicos, sociales y culturales, indispensables a su dignidad y al libre desarrollo de su personalidad.

Desde el punto de vista de los derechos humanos, la diversidad cultural tiene innegables limitaciones. Cuestionar hasta qué punto la autonomía de las culturas de los países de acogida pueden restringir o limitar los derechos y libertades de sus miembros sean o no nacionales supone un reto a alcanzar por parte de las políticas públicas en materia de inmigración. La respuesta no es sencilla, por un lado, porque establecer un diálogo cultural en donde ya de entrada existe una primacía en la cultura identitaria hegemónica resulta difícil, 
primordialmente a la hora de asumir criterios de cohesión en clave de identidad cultural; además, se ha de tener en cuenta qué culturas y sistemas identitarios han de respetarse y perpetuarse; y por otro lado, hay que recordar que si no se respeta el ideario de los contenidos reconocidos por los derechos humanos de forma generalista, no puede hablarse de derechos universales.

La perspectiva de la identidad cultural juega un papel clave en el diálogo intercultural, así como en la adopción de medidas que detenten unos mínimos exigibles de reconocimiento a todas las culturas. De lo contrario, resulta incompatible con el discurso de los derechos humanos la existencia de grupos con situación de inseguridad o discriminación, por no compartir con la o las culturas hegemónicas sus tradiciones culturales.

\section{EL DILEMA DE LA DIVERSIDAD}

La aspiración de alcanzar una sociedad relativamente homogénea en materia de derechos y deberes, se ve alterada por la exclusión social de determinados colectivos. La diversidad cultural, en algunos casos, lleva consigo una barrera de diferenciación entre los sujetos que forman parte del país de acogida "nacionales", de los que no los son, dejando al margen a sujetos cuya exclusión ya de entrada, supone una discriminación en la atribución de derechos.

Gómez Ciriano $(2010,85)$ propugna una serie de cuestiones válidas para esa conformación generalista de los derechos, teniendo en cuenta la tesis cultural de cada uno de los grupos objetivo. Así entiende "se debe poner el énfasis en el individuo y no en las comunidades. Afirmando que es necesario hablar menos de políticas multiculturalistas centradas en las comunidades y hablar más de políticas de integración, de cohesión social y de ciudadanía compartida centradas en el individuo".

De hecho, sirva como ejemplo, que no pocos autores defienden que se debe ser especialmente riguroso con las políticas de reagrupación familiar. Resaltando la necesidad de evitar como consecuencia directa en la entrada en el país acogente, personas que no tienen un dominio suficiente de la lengua del país de destino o que ignoran su cultura o modo de vida. Puesto que se corre el riesgo, tanto por parte del reagrupante como los reagrupados acaben encerrándose en sus comunidades, promoviendo grupos étnicos o culturalmente diferenciados, perdiendo así oportunidades para la integración y para la inserción en el mercado laboral (Gómez, 2010, 92). 
En esa línea de concreción de bases mínimas de acceso del inmigrante al país de acogida, que no se rechazan plenamente, resulta lógico establecer una suerte de condicionamientos previos y generalistas, no podemos obviar frente a ello, sin embargo, que todo refuerzo social a la integración del inmigrante debe constituirse en un marco legítimo de derechos y deberes, pues solo así, la confluencia de las culturas en las sociedades puede entenderse tenga aceptación general.

Por su parte, el reconocimiento del artículo 10.1 de la Constitución española de 1978 del valor de la dignidad personal, coloca en una posición que no diferencia a los españoles de los que no lo son. Es la razón por la que el valor de la dignidad personal se convierte en el punto de referencia inmediato para el respeto de los derechos y garantías que asisten a todos los sujetos frente a las injerencias externas o incluso del propio Estado.

Debiendo trasladar esa idea de dignidad a cualquier previsión legal que se haya de aplicar en sede de integración del inmigrante y en el propio desarrollo de su cultura en un ámbito neófito y extraño, incluso a la hora de plasmar esos condicionamientos mínimos y generalistas aplicables al acceso inicial al país acogente.

Pues se parte de la idea que responde al respeto principal a la dignidad de cualquier ser humano, con independencia de su nacionalidad, género, raza etc., y que cobra sentido en la obra de Peces Barba $(2001,29)$ cuando afirma que la dignidad supone el valor fundacional y núcleo conceptual de los derechos humanos.

Otro tanto, habría que decir en relación al libre desarrollo de la personalidad, noción íntimamente vinculada con el valor que asume la dignidad humana. Y es que al ser el concepto de persona y personalidad conceptos universales, no tiene sentido que se diferencie su libre desarrollo en función de su nacionalidad, ni del lugar de proveniencia, ni que pueda situar al sujeto como ser desprovisto del estatus necesario que proporciona la residencia legal en un determinado país.

Las cuestiones de nacionalidad y de inmigración son asumidas por el Estado, en legítimo cumplimiento de la Constitución española de 1978, que señala en su artículo 149.1.2ㅇqu "el Estado tiene competencia exclusiva sobre las siguientes materias: nacionalidad, inmigración, emigración, extranjería y derecho de asilo". De este modo, la Constitución española de 1978 y los Tratados Internacionales ratificados por el Estado español determinarán el estatus de los derechos y libertades que ostentan los inmigrantes en España.

En este sentido, cabe la posibilidad refrendada por los hechos de estos últimos tiempos, particularmente en Europa, de que esa decisión del Estado sea una decisión restrictiva de los 
derechos fundamentales del inmigrante. Pues, como lamentable ejemplo, resulta notoriamente restrictivo el estricto sistema de control de fronteras que imposibilita poner en práctica el mismo derecho a emigrar de un país a otro a los ciudadanos extracomunitarios que al resto de ciudadanos de la Unión Europea. De modo que los países miembros de la Unión, de forma unilateral, aunque compartida en mayor o menor medida con otros países del entorno europeo, deciden hacer reserva del derecho de admisión de inmigrantes (Souto, 2014, 16), cerrando las puertas a su entrada de forma taxativa y criminalizante. Eso supone, además, entender que se está restringiendo el ejercicio del derecho al libre desarrollo de la personalidad del inmigrante, por cuanto este derecho implica decidir sobre su situación personal y espiritual.

Al fin y al cabo, la esencia del libre desarrollo de la personalidad, como derecho, es el reconocimiento que el Estado hace de la facultad natural de toda persona a ser individualmente como quiere ser, sin coacción, ni controles injustificados o impedimentos por parte de los demás. El fin de ese derecho es la realización de las metas de cada individuo de la especie humana, fijadas autónomamente por el mismo sujeto, de acuerdo con su temperamento y el carácter propio, con la única limitación de los derechos de las demás personas y del orden público.

El inmigrante no va a tener la misma capacidad de desarrollo autónomo que el Estado reconoce, sin ningún tipo de problemas a sus nacionales. En este sentido, habría que entender que el inmigrante es objeto de una manifiesta discriminación que parece contradictoria desde luego con el espíritu igualitario que se supone que han de presidir los sistemas jurídicos y políticos en territorios que se reconocen a sí mismos como democráticos.

La propia Constitución española de 1978 parte de una construcción jurídico- política donde reconoce en su artículo 1.1 un modelo de Estado como social, democrático y de derecho (Balaguer et al, 2002, 89). En su concreta expresión, el modelo estatal democrático de derecho debe suponer un instrumento eficaz en el reconocimiento de los derechos humanos fundamentales para el sujeto con carácter general y en particular al sujeto inmigrante. Ello, responde a la idea del carácter social e igualitario en el que se fundamenta el modelo democrático de Estado cuyo objetivo es el establecimiento de garantías a todos los sujetos con independencia de su nacionalidad o cultura identitaria.

Precisamente por ello, puede afirmarse que se produce una vulneración flagrante del principio de universalidad de los derechos humanos que carece de sentido cuando, como sucede en el caso del artículo 10.1 de la Constitución española de 1978, toma como punto de referencia los conceptos de persona y personalidad. Esta transgresión es tanto más grave 
porque se produce en perjuicio de un colectivo de personas especialmente frágil y vulnerable como es el caso de los inmigrantes. La restricción del ejercicio del libre desarrollo de la personalidad y de los demás derechos del inmigrante supone un acto de imposición del fuerte sobre el débil, un ejercicio imperial de la fuerza, una opresión institucionalizada, que es precisamente lo que trata de evitar la activación de los presupuestos inherentes a la ideología de los derechos humanos.

La tesis de Luigi Ferrajoli cobra aquí todo su sentido, $(2001,369)$ cuando habla de los derechos fundamentales como "leyes del más débil frente a la ley del más fuerte". La defensa del libre desarrollo de la personalidad del inmigrante y de los derechos que ese principio proyecta, cuya titularidad resulta inherente a la condición humana, se plantea de imposible cumplimiento, ante la inexplicable, y desde luego condenable, actitud de un Estado o unión de Estados, que muchas veces se muestran obcecados en tratar al inmigrante como si se tratara de un sujeto inferior, "prepeligroso", en comparación con el resto de los individuos que integran la comunidad social de referencia.

Siendo en esa línea, una utopía perfecta, la denominada integración activa, "modelo europeo que se inicia en la década de los 90 en Holanda y Dinamarca y se ha ido extendiendo a otros países como Austria, Bélgica, Francia, Alemania o Suecia. Pues pese a la denominación que ostenta, integración activa, parte de la doctrina sostiene que se trata de una derivación del asimilacionismo tradicional y duda de sus posibilidades de integrar desde la interculturalidad en cuanto los esfuerzos hacia la integración se centran en exclusiva en homogenizar ${ }^{2}$ al inmigrante, arrinconando su propia identidad cultural en aras de lograr evitar los supuestos conflictos de convivencia que se achacan a la presencia de diversidad cultural en el seno de la sociedad de acogida" (Souto, 2014, 16). Estableciéndose con ello, una evidente minusvaloración del ciudadano inmigrante frente al que no lo es.

Así, "el concepto de ciudadanía se presenta aquí como la coartada perfecta para la exclusión. Es una acepción que tiene una larga tradición en la historia de los derechos humanos, pero que ahora precisamente va a operar como criterio, como módulo supuestamente objetivo, no sólo en lo que concierne a la realización práctica de los derechos, sino incluso en lo que directamente atañe a la titularidad de los mismos. La ciudadanía viene así presentada como el último privilegio de estatus, el último residuo premoderno de las diferenciaciones personales, el último factor de exclusión y de discriminación, y no, como sucedió en el origen de los Estados

\footnotetext{
2 Expresión añadida por la autora del artículo.
} 
modernos, de inclusión y de igualación, la última contradicción irresuelta con la proclamada universalidad de los derechos fundamentales" (Ferrajoli, 2001, 32). Es, por lo demás, un factor de exclusión que cuenta con toda la fuerza del ordenamiento jurídico nacional que lo respalda, en definitiva, la "forma legal de exclusión" (Solanes, 2001, 238). En este sentido, se ha podido decir que en la concepción actual de la ciudadanía "prevalece la exclusión sobre la inclusión, más aun la regulación sobre la emancipación" (Seco, 2007, 330).

El concepto de ciudadanía cobra un papel sumamente notorio sobre todo en el Estado moderno, puesto que resulta difícil asumir una concepción unitaria de grupos societales que no guarden una uniformidad en cuanto a su cultura identitaria. Por ello, la ciudadanía se presenta como una identidad entre de los individuos en el espacio público, valiendo como soporte central en la construcción formal del Estado y los grupos sociales (Thiebaut, 1998, 24), unidad más teórica que práctica, pues como se afirma, la ciudadanía es un concepto que proyecta desigualdad, cuando obtenerla (aunque sea esa ciudadanía de segunda que indicamos existe para algunos inmigrantes), significa un calvario extenuante de documentación y trámites burocráticos amén de otras exigencias, frente a quien por el mero hecho de nacer en un territorio, adquiere la calificación de ciudadano de primera.

Ese trato desigual se proyecta a su vez en un crecimiento exponencial de la discriminación del desfavorecido en la distribución de los derechos. Luigi Ferrajoli ha expresado a este respecto que "existe un nexo profundo entre democracia e igualdad, y a la inversa, entre desigualdad en los derechos y racismo; del mismo modo que la igualdad en derecho genera el sentido de la igualdad basada en el respeto del otro como igual, la desigualdad en los derechos genera la imagen del otro como desigual, o sea, inferior en el plano antropológico, precisamente por ser inferior en el plano jurídico" (Ferrajoli, 2001, 44).

Esa imagen de sujeto discriminado como un sujeto inferior no sólo se proyecta sobre los miembros de la sociedad de acogida, aunque puedan cuidarse mucho sus integrantes de hacer explícito el sentimiento que tienen, sino también, en gran medida, sobre el propio inmigrante. Los miembros de la sociedad de acogida se sienten, en cierto modo, superiores al recién llegado, que muchas veces es abierta e indisimuladamente considerado como un ser inferior, perteneciente a una cultura que en su opinión no tiene el mismo nivel de desarrollo y adecuación que la concreta cultura en que ellos han ido desarrollando su vida. A su vez, el inmigrante podrá también experimentar un sentimiento de inferioridad y apocamiento que a la larga dificultará incluso el ejercicio de aquellos derechos cuya titularidad acepta concederles, siquiera sea a regañadientes, la sociedad de acogida. Cuestión notoriamente constatable si se 
tienen en cuenta, las diversas aclaraciones públicas sobre la titulación y demás garantías personales de los ciudadanos sirios que fueron acogidos por los distintos Estados de la Unión europea. Lo cual viene a demostrar, lamentablemente, que incluso hay escalas de reconocimiento entre inmigrantes, cuestión que no va a ser tema de referencia de este trabajo, pero que no puede pasarse por alto.

En estas condiciones, lo lógico sería que las políticas de inmigración que emprendieran los países receptores se esforzaran por asumir el punto de vista de la realización personal del inmigrante, que es quien realmente se encuentra en peligro grave de exclusión. La gran paradoja es que, sin embargo, estas políticas de inmigración hacen a la hora de la verdad caso omiso, en general del propio valor personal del inmigrante para centrarse prioritariamente en la preservación de los intereses de los individuos que integran la sociedad de acogida (Miraut, 2004, 333). Las políticas de inmigración constituyen, en sí mismas, un instrumento más para la consolidación de una situación de desigualdad, que nos traslada la idea de que si tomáramos en serio el principio de universalidad de los derechos humanos, habría que intentar corregir radicalmente la situación.

Se ha señalado con mucha frecuencia que el concepto de ciudadanía nacional, presupuesto a su vez de la diferenciación de regímenes de titularidad y de realización de los derechos humanos, según se trate de ciudadanos nacionales y extranjeros, resulta a la hora de la verdad ineliminable, porque va asociado a la propia organización del mundo que, como tal, no podría cambiar. Esta afirmación es, sin embargo, absolutamente engañosa. Es cierto que la actual organización del mundo propicia un sistema de redistribución desigual en muchos ámbitos, también en el de los derechos fundamentales. Pero la constatación de la existencia de un determinado hecho no constituye ningún argumento razonable para su consagración como una situación ilegítima. No todo lo que sucede en la realidad política, está legítimamente justificado. Es más, la confirmación de que esa distribución del mundo pueda resultar ilegítima o injusta es una razón de peso para la exigencia de que se proceda de manera inmediata a su modificación por los Estados y las políticas estatales y supraestatales.

Prueba obvia de esa diferenciación, es que en el llamado régimen comunitario se encuentran incluidos, los ciudadanos miembros de los países de la Unión, los ciudadanos pertenecientes a los Estados miembros del Acuerdo sobre el Espacio Económico Europeo, los ciudadanos de Noruega, Islandia y Liechtenstein y los ciudadanos suizos en función del Acuerdo sobre libre circulación de personas entre Comunidad Europea y Suiza. 
Pues aunque la Unión Europea prohíbe toda discriminación por razón de nacionalidad respecto a los nacionales de los Estados miembros, sin embargo, tiene establecido un régimen desigual para nacionales de terceros países. Teniendo como consecuencia inmediata, la distinción en el ámbito de la ciudadanía entre extranjeros comunitarios y extranjeros extracomunitarios.

No obstante a ello, el obstáculo que representa la diferenciación ciudadana y la identificación de sistemas jurídicos de garantías de los derechos fundamentales, que vienen a diferenciar entre derechos de los ciudadanos nacionales y derechos de los extranjeros no es, ni mucho menos, un obstáculo que deba considerarse insalvable. En el fondo, su superación dependerá casi exclusivamente de la voluntad política de quienes ostentan el poder. Esta voluntad ha de buscar la realización de un proyecto igualatorio y cosmopolita. Teniendo muy en cuenta que la realización de ese proyecto se encuentra al alcance de la mano de los individuos.

Así, apoderar a los ciudadanos en su elección de vida tiene resultados garantistas para éstos, puesto que la toma de decisión se hace de forma común y participativa. Esa participación de todos en la visión que quieren a futuro en materias como la ciudadanía y los derechos y obligaciones comunes que han de respetarse, pasa por la aplicación externa y concluyente de derechos de igualdad ciudadana. Primordialmente teniendo en cuenta la efectiva realización de esa igualdad y unidad participativa del ciudadano, para y por "todos los tipos y niveles" de ciudadanos. Haciendo con ello, una realidad tangible la activa colaboración social de todos y cada uno de los miembros de la comunidad, de forma igualitaria y amplia.

Por otro lado, en ocasiones parece una paradoja auténtica la petición de este tipo de desarrollo político y participativo de la sociedad. Cuando es una necesidad que debe darse de continuo de un modo palpable, visible y constatable; y además, a todos los niveles políticos, local, nacional y supranacional. Sin que quepa aducir capacidad de nula realización o irrealización de estos derechos de igualdad y participación pública, bajo ningún concepto o excusa.

En ese mismo sentido, lo ha visto Luigi Ferrajoli $(2001,337)$ cuando expresa que"no es una objeción teórica sino una petición de principio la del carácter irrealizable y, por consiguiente, utópico de la perspectiva de un orden mundial basado en instituciones internacionales idóneas para garantizar la igualdad de todos los seres humanos en los derechos de la persona, a causa de los intereses políticos y económicos que se oponen a la misma y que coinciden, evidentemente, con los de los países más ricos y poderosos que bien realizarla con sólo quererla. Si no quieren eludir u ocultar (nuestras) responsabilidades políticas y de cultura 
jurídica y politológica, es preciso en efecto distinguir entre pesimismo y realismo, entre lo que no se quiere realizar, por lo que verosímilmente, no será realizado, y lo que es irrealizable ya que, por pesimistas que puedan ser las previsiones sobre la perspectiva de la igualdad de los seres humanos en los derechos fundamentales, nada autoriza a afirmar que la misma sea irrealista o irrealizable. Su realización depende únicamente, de la política, de la voluntad de los países económica y militarmente más fuertes, pero también de las luchas políticas y sociales de las masas hoy discriminadas, así como, del apoyo que les presten las fuerzas democráticas de los países privilegiados".

Pues, según afirma De Lucas (2004, 211), el inmigrante extracomunitario se encuentra en una condición jurídica inferior a la de los comunitarios y nacionales y, en este sentido, se ha puesto de relieve su configuración como "infrasujetos, puesto que su reconocimiento jurídico y político está condicionado a un modelo de trabajo, que ni siquiera es válido para los propios autóctonos. El vínculo entre nacionalidad, trabajo y ciudadanía aparece así como la auténtica jaula de hierro de la democracia".

Es por ello, que tal que como afirmara Solanes $(2006,1)$, "se ha de partir de la idea de que no es posible la integración sin derechos, es decir, sin el reconocimiento de un estatuto jurídico pleno para los extranjeros que obliga, por una parte, a superar las situaciones de exclusión estratificada de colectivos como los inmigrantes irregulares, y por otra, a incluir en el catálogo jurídico de los extranjeros, derechos de participación política”. Se trataría finalmente, de transformar la categoría de inmigrante para pasarla de objeto a sujeto de Derecho, consiguiendo así una aplicación del principio de igualdad en su máxima extensión.

\section{LAS POLÍTICAS PÚBLICAS DESIGUALITARIAS}

Las políticas públicas de inmigración en los Estados occidentales se manifiestan como propuestas destinadas a hacer viable la consolidación de una situación de hecho, que resulta absolutamente censurable desde el punto de vista de la propugnada realización del principio de universalidad de los derechos humanos. Son generalmente políticas programáticas decididas por los órganos representativos de las sociedades de acogida, sin tomar en cuenta, la opinión de los grupos representativos de inmigrantes, ni organizaciones conocedoras en materia de integración y desarrollo social. Tomando en consideración la opinión que al respecto podrían tener ámbitos cercanos y especializados en ese concreto ámbito, dándole así voz al propio inmigrante y a su entorno. 
Por otro lado, los defensores de las tesis paternalistas podrían esgrimir que esa exclusión del inmigrante en el proceso de determinación de sus derechos, obedece a una supuesta falta de competencia o capacidad del inmigrante para decidir acerca de lo que le conviene. Así, las políticas públicas de inmigración tratarían de suplir la falta de competencia del inmigrante para garantizarle una realización integral de sus intereses que el propio inmigrante no podría llegar ni siquiera a vislumbrar con claridad. Pero ello requeriría, además de la prueba de la supuesta incompetencia o incapacidad, que el inmigrante resultara efectivamente beneficiado por esa determinación ajena de sus derechos, cosa que evidentemente no sucede en ese caso.

No cabe en ese sentido, que se hable de una determinación de los derechos beneficiosa o favorable a los intereses del inmigrante cuando, de hecho, se le está discriminando al negarle la titularidad de ciertos derechos, fundamentalmente los denominados derechos de participación política. Derechos, por otro lado, de gran influencia sobre la implementación o definición del resto de posibles derechos a adquirir en la práctica, imponiéndose también por tanto, significativas restricciones en lo que concierne al ejercicio de derechos cuya titularidad sí se les reconoce, sin embargo, en el plano formal.

En este sentido, se puede decir que la exclusión del inmigrante del proceso de determinación de sus derechos va mucho más allá de lo que puede ser una exclusión técnica, establecida paternalistamente para favorecer la realización de su propio bien, de lo que quien diseña y pone en práctica las políticas públicas de inmigración entiende que le conviene al inmigrante. Es una exclusión interesada que, muy al contrario, parte de la idea de que si estuviera en sus manos la adopción de la correspondiente decisión, el inmigrante tendría mucho interés en reivindicar para sí mismo los derechos que la sociedad de acogida reserva en exclusiva a sus propios ciudadanos.

El inmigrante resulta así, doblemente discriminado con respecto a sus derechos. Por un lado, se le excluye directamente de cualquier participación activa en el proceso de determinación de sus derechos. Por otro, la decisión que toman quienes se atribuyen el poder al respecto, es una decisión que, a la hora de la verdad, resulta indiscutiblemente perjudicial para los intereses del inmigrante. Lo más enojoso de la situación descrita es que ese carácter perjudicial para sus intereses no sólo es así entendido por el inmigrante, como persona directamente afectada en el problema, sino también por los ciudadanos originarios de la sociedad de acogida que se autoatribuyen conscientemente, así el poder de vulnerar de la 
manera más flagrante las exigencias que impone el principio de universalidad de los derechos humanos.

En este sentido, las políticas de inmigración con relación a los derechos humanos habrán de partir, ante todo, de ese hecho evidente. Se produce una discriminación de los inmigrantes tanto en el plano de la titularidad como en el plano de la realización de los derechos. No se les reconoce como titulares de todos los derechos que son normalmente considerados como derechos universales, y además, la efectiva realización de los derechos sobre los que sí se les reconoce titularidad, es una realización pobre, de menor intensidad que la realización de los derechos de los nacionales del país. La decisión pública que determina la identificación de los derechos comunes a todos los ciudadanos, o en su caso, los criterios de distribución de los derechos entre los residentes, legales o ilegales, en la sociedad de acogida, resulta ser una decisión ajena a la participación de los inmigrantes.

Se trataría así, de proponer la recuperación del poder autónomo del inmigrante para decidir cuáles son las exigencias inherentes a la satisfacción de las necesidades individuales. Un poder que en el fondo, no habría de ser diferente del poder que tiene cualquier individuo por su propia condición como miembro, formal o informal, del grupo social en el que desarrolla su convivencia. Así, el profesor De Asís Roig $(2002,544)$ pone el acento en "los rasgos que permiten proyectar la idea de la autonomía moral de las personas, que se traduciría en la anteposición de la libertad ideológica y de conciencia a cualquier otro criterio fundado en razones de pertenencia nacional o cultural, la igualdad de trato de todos los individuos como participantes en la decisión relativa al modo correcto de entender los derechos y la satisfacción de las necesidades subsistenciales que permitirán al individuo plantearse algo más que la mera supervivencia física".

Se ha de poder reconocer que las políticas públicas de inmigración que no asuman como guía de actuación la satisfacción de estos tres criterios (anteposición libertad ideológica, de conciencia, de nación o cultura y la igualdad de trato), difícilmente, podrían considerarse como políticas inmigratorias que superan el contraste de la teoría de los derechos humanos. Serían políticas públicas de inmigración que no considerarían la condición humana del inmigrante en toda su integridad, como sujeto digno de tener derechos y de participar activamente en la decisión relativa a los derechos reconocidos como derechos universales.

El primer paso, en este sentido, sería diferenciar lo que son políticas públicas de inmigración y políticas públicas de inmigración respetuosas con la teoría de los derechos humanos. Evidentemente, estas últimas tendrían un plus de legitimidad que faltaría a las 
primeras. Y es que, cabe ciertamente perseguir con las políticas públicas de inmigración otros objetivos diferentes a la realización de los derechos del inmigrante. Pero lo que no cabe, al menos si se admite a la dignidad del individuo y a los derechos humanos como criterio de legitimación, es la existencia de políticas públicas de inmigración que resulten contradictorias y vulneradoras de las exigencias que impone el principio de la universalidad de los derechos humanos.

El reconocimiento del derecho al libre desarrollo de la personalidad del individuo como un derecho universal sitúa en este sentido, al libre desarrollo de la personalidad del inmigrante como un criterio básico que inexcusablemente habrán de cumplir las políticas públicas de inmigración que pudieran emprender las sociedades receptoras. Es, en definitiva, un presupuesto básico para la legitimación de cualquier política pública de inmigración. Los miembros originarios de las sociedades receptoras deberían tenerlo muy presente a la hora de elaborar el juicio crítico relativo al modo en que el Estado afronta el desafío que supone la creciente intensidad del fenómeno inmigratorio. O bien, como establece Ángeles Solanes (2006, 2), lo que se necesitaría es la "la configuración de un estatuto jurídico pleno que permita articular la integración del inmigrante, entendiendo que ésta es consecuencia del cúmulo de libertades, puesto que no puede haber integración sin derechos (...)".

\section{CAUSAS DE LA PRETERICIÓN DEL LIBRE DESARROLLO DE LA PERSONALIDAD EN EL MARCO DE LA REALIZACIÓN DE LAS POLÍTICAS DE INMIGRACIÓN}

Como se ha apuntado, las políticas de inmigración asumen, en general, el punto de vista de los intereses de los miembros de la sociedad de acogida, ocupándose sólo de la realización de los intereses exclusivos de ese concreto grupo.

El ciudadano inmigrante nace cuando un ciudadano nacional de cualquier país, movido en muchas ocasiones por razones de necesidad de subsistir con un mínimo de dignidad, decide trasladar su residencia a un nuevo entorno social en otro Estado, que le ofrezca mayores posibilidades de realización personal.

Las políticas públicas de inmigración en los países acogentes europeos resultan ser, en este sentido, unas políticas inevitablemente discriminatorias. La sociedad de acogida suele esgrimir a la hora de articular sus políticas de inmigración unos objetivos supuestamente legitimadores de la discriminación que, como vamos a comprobar, caen por su propio peso. 
En este sentido, la profesora Miraut $(2004,334)$ refiere que, como objetivos declarados, aun cuando no justificados, de las políticas de inmigración propugnadas y emprendidas en las sociedades occidentales, se encuentra la preservación de la seguridad personal de los nacionales de la sociedad de acogida, la consagración del nivel de vida alcanzado en la misma y la salvaguarda de los fundamentos básicos de la civilización propia.

Por su parte, afirma Solanes (2006, 2), que el círculo vicioso y progresivo de exclusión del que ha sido objeto la persona inmigrante sólo puede romperse si se comienza, como propone De Lucas $(2003,52)$, por negar la mayor de las premisas, afirmando que "es más que cuestionable el hecho de que todo extranjero procedente de otro cultura deba ser visto como un enemigo, del mismo modo que también lo es que los países que acogen inmigrantes tengan una cultura homogénea y consolidada a la que la persona inmigrante pueda "apuntarse" (¿asimilarse?) como un todo".

Además, se supone de forma automática como correcta la advertencia de que la llegada de los inmigrantes genera un deterioro de la seguridad personal de la población autóctona, y toma como punto de partida la consideración de las dificultades económicas que sufren los inmigrantes en la sociedad de origen, las dificultades que les mueven a abandonar de manera prácticamente forzada su entorno natural, y que cuando no alcanzan un puesto de trabajo suficientemente remunerado, reproducen en buena medida en la sociedad de acogida situaciones generadoras de inseguridad social de su país de origen.

La prevención frente a la posible producción de este deterioro de la seguridad personal de los habitantes del lugar se encuentra absolutamente exacerbada en las sociedades occidentales, pudiendo afirmarse con De Lucas $(2002,30)$, que las políticas de inmigración que se emprenden en ellas "cada vez más parecen presas del síndrome securitario". Un síndrome que deriva en el mayor perjuicio de quienes son injustificadamente considerados como causantes directos de esa insatisfactoria situación.

La lamentable situación se muestra con toda claridad en "la inversión del principio de inocencia" que se produce en relación al inmigrante, obligado a demostrar que no es un peligro, ni para la seguridad personal ni para la pervivencia de los valores firmemente consolidados en la cultura occidental (De Lucas, 2004, 42) y en la acentuación del carácter negativo de la imagen que proporciona en general las informaciones publicadas en los medios de comunicación con respecto al fenómeno inmigratorio (Van Dijk,2009, 52). Es un síndrome que parece olvidar además el hecho cierto de que el inmigrante es también víctima de delitos y no sólo actor de los 
mismos, sobre todo, en un ámbito en el que su situación de debilidad le hace especialmente propenso al abuso por parte de los miembros de la sociedad receptora ${ }^{3}$ (Calvo, 2004, 183).

La cuestión no es, sin embargo, tan sencilla como a simple vista parece, para empezar, porque se trata de un problema que se ve redimensionado en su importancia porque proporciona una visión que interesa al Estado porque éste reconoce en ella su propia legitimidad (Calvo, 2004, 242). No puede tampoco decirse que el inmigrante sea una persona naturalmente hostil a la sociedad de acogida porque eso iría en contra de sus intereses más directos que son precisamente su integración en la misma (Winckler, 1999,156).Y tampoco, puede encontrarse la solución adecuada al problema en la salida fácil que representa la eliminación sin más del fenómeno inmigratorio. Está claro que las diferencias de bienestar que puedan existir en cualquier grupo social constituyen un fuerte estímulo para la violencia y la delincuencia. Pero ello no justifica el establecimiento de medidas de discriminación de derechos. Lo más lógico es atajar el problema en su raíz, evitando que se produzcan situaciones de miseria tan lamentables que impulsen a los individuos que las sufren en sus propias carnes a abandonar su sociedad originaria para procurarse un futuro mejor para ellos mismos y para sus familias.

Claramente el problema de la realización de ese programa conlleva un costo para la sociedad de acogida, en la medida en que promueve la eliminación de los privilegios que sus nacionales tienen con respecto a los habitantes del tercer mundo. Es un costo que la sociedad de acogida se niega, desde luego, a pagar; asumiendo con la mayor naturalidad las diferencias económicas entre unos y otros.

Así, puede afirmarse que resulta muy cómodo decir que la llegada del inmigrante produce un notable incremento de la inseguridad personal de los habitantes del lugar, cuando a la hora de la verdad, esa inseguridad personal es consecuencia directa del establecimiento de una situación de hecho ilegítima e injusta que la sociedad de acogida, teniendo en su mano hacerlo, se niega sistemáticamente a modificar.

Lo cierto es que, persistiendo esa situación de discriminación económica entre los habitantes de unos y otros países, el traslado de los perjudicados por razón de nacimiento a los países más ricos y desarrollados es un hecho constatable, que mientras no cambien las circunstancias difícilmente se alterará. Como bien se ha dicho, "la inmigración en masa es un

\footnotetext{
${ }^{3}$ El autor señala que "es evidente que el inmigrante no sólo es sujeto pasivo. También es usuario de la justicia desde la perspectiva contraria- como denunciante víctima. Esta conclusión rompe con el estereotipo del inmigrante delincuente, para evidenciar la relevancia del inmigrante-víctima".
} 
fenómeno no sólo irresistible, sino destinado a crecer de manera exponencial hasta tanto no se haga frente con seriedad a sus causas económicas y sociales" (Ferrajoli, $(2005,176)$. En este sentido, puede decirse que el fenómeno migratorio "ha alcanzado en la actualidad la dimensión de factor estructural en una sociedad globalizada y en la que la dualización entre un norte cada vez más rico y un sur que no deja de empobrecerse, lejos de estrecharse, continúa profundizándose" (De Lucas, 2001, 141).

Ante estas circunstancias, consciente de las razones reales que genera la inseguridad personal que se esgrime en contra del inmigrante, Miraut (2004, 334-342) propone las siguientes medidas. En primer lugar, proporcionar al inmigrante un nivel de vida mínimo que le permita evitar encontrarse en situaciones que puedan considerarse de estado de necesidad. En segundo lugar, hacer al inmigrante partícipe del proyecto social general, posibilitando así la toma de conciencia por su parte de las ventajas que la realización de ese proyecto social le puede generar a él mismo. En tercer lugar, realizar las acciones tendentes a evitar que el inmigrante sienta la necesidad de defenderse de la sociedad de acogida integrando guetos de la marginación cuya existencia es muchas veces alentada por la propia sociedad de acogida. En cuarto lugar, la aceptación de un programa de solidaridad interregional, comprometiendo a todos en el tema de la acogida de la población inmigrante, de manera que no haya regiones de la sociedad de acogida que contemplen la llegada de los inmigrantes como un tema que, por su condición de frontera, les afecta a ellas en particular, y del que, sin embargo, se desentienden a la hora de la verdad, los habitantes de otras regiones del mismo país o "unión de países" ${ }^{4}$. Y finalmente la puesta en marcha de un proyecto educativo que promueva el conocimiento del diferente, de su cultura y de sus experiencias vitales, como un conocimiento enriquecedor para la propia sociedad de acogida.

Por otro lado, puede afirmarse con la profesora Miraut (2004, 339-340), que las políticas de inmigración asumen muchas veces, expresa o tácitamente, el mantenimiento del nivel de vida de la sociedad de acogida como uno de los principales criterios rectores de su orientación. El mantenimiento del nivel de vida tiene, en cualquier caso, al menos dos proyecciones diferentes según se manifieste como mantenimiento del nivel de vida económico o como mantenimiento del nivel de vida medioambiental.

La preservación del nivel de vida desde el punto de vista económico apunta al hecho indiscutible de que la llegada de los inmigrantes provoca nuevas necesidades de atención social

\footnotetext{
${ }^{4}$ La referencia "unión de países", en clara referencia a la Unión Europea es añadido por la autora del artículo.
} 
por un lado y la necesidad de repartir con ellos los puestos de trabajo por otro. Se suele tratar de diluir el sentido del primer hecho alegando el dato de que, si bien es cierto que los inmigrantes se benefician de los servicios sociales existentes en la sociedad receptora, no es menos cierto que ellos mismos contribuyen en buena medida con sus aportaciones a su mantenimiento. En este sentido, se observa que las tasas de envejecimiento de la población original de las sociedades occidentales aconsejan la urgente incorporación de población agregada en su territorio que contribuya a asentar el funcionamiento futuro del sistema, lo que quedaría ejemplarizado en la idea de que "aceptar la inmigración supondría en este punto una rentable inversión social" (Miraut, 2004, 340). Es lo que se ha venido a reconocerse como una de las paradojas más sobresalientes del fenómeno inmigratorio. Se pronuncia en este sentido, Pérez de la Fuente $(2006,256)$ cuando defiende que "la paradoja del inmigrante como freerider consiste en sostener un discurso sobre los efectos económicos negativos de la inmigración mientras se constata, por el contrario, que la inmigración aumenta la riqueza y que, tras el discurso sobre la ilegalidad de la inmigración, se esconde su rentabilidad económica. Esta paradoja tiene el sentido de ir contra la opinión común que afirma que los inmigrantes se aprovechan de las ventaja de las economías prósperas, cuando es el mercado el que extrae beneficios de su situación subordinada".

Por otro lado, se señala también que la llegada de los inmigrantes contribuye al mejor funcionamiento del mercado de trabajo en la medida en que los recién llegados aceptan normalmente la realización de tareas de las que no se quieren ocupar los miembros de la sociedad de acogida. Son, sin embargo, tareas que resultan absolutamente imprescindibles para la garantía del progreso y el bienestar de la propia sociedad de acogida, y que alguien tendría, en todo caso, que llevar a cabo.

El planteamiento del problema en estos términos resulta, no obstante, insatisfactorio. Está claro que los miembros de la sociedad de acogida pueden verse materialmente favorecidos por el fenómeno de la inmigración. Pero éste no es el mejor argumento que se puede esgrimir para la defensa de los derechos del inmigrante. Este planteamiento supone darle a la sociedad de acogida una legitimidad de la que carece, para adoptar decisiones que incumben a los derechos de los inmigrantes en función de sus propios intereses. Las cuestiones relativas a los derechos de cualquiera, sea o no un inmigrante, deberían de tomar como punto de partida su propia condición de persona, condición común a los individuos de todas las sociedades, y no la pertenencia o no a un determinado grupo social por razón de nacimiento. Es el principio de universalidad de los derechos humanos el que impone la exigencia inderogable de que no se 
discrimine a ningún sector de la población, cualesquiera que sean las circunstancias de nacimiento, edad, sexo, residencia, nacionalidad, etc., de los individuos de que se trate.

Y éste es el argumento que habría que esgrimir para rechazar de pleno las alegaciones formuladas por quienes constantemente manifiestan que la llegada de los inmigrantes puede perjudicar el nivel económico que en un momento determinado han conseguido alcanzar los miembros de la sociedad de acogida. La argumentación de las ventajas adicionales que de la implantación de ese hecho puedan obtener los miembros de la sociedad de acogida es una salida en falso del problema, una manifestación del deseo de no contemplar la necesidad de preservar los imperativos del principio de universalidad de los derechos humanos frente a los intereses ilegítimos de terceros (Miraut, 2004, 340-342).

Pues, el problema que suscita la necesidad de preservar el nivel de vida medioambiental tiene una condición muy diferente. Parece en principio razonable pensar que tampoco el crecimiento demográfico que diera lugar a una situación de superpoblación en una determinada zona geográfica es razón suficiente para restringir sin más la intensidad de la realización de los derechos de los inmigrantes, empezando por la realización del derecho a salir de la situación económica en que se encuentra, instalándose en la sociedad de acogida.

Pues bien, según Solanes $(2006,5)$, "si la irregularidad domina el panorama migratorio y justifica reducciones legales de derechos y libertades, combatirla ha de ser una prioridad política. En todo caso, si se me permite la comparación, no se acaba con la esclavitud "matando" al esclavo, de igual modo no se combate la clandestinidad agrediendo al inmigrante irregular, sino incidiendo sobre los múltiples factores que lo convierten en tal, como por ejemplo, la legalidad de difícil cumplimiento práctico, las mafias que la aprovechan, o la potente atracción de un mercado informal de trabajo poco combatido".

Además no puede obviarse, como señala Sassen $(2001,95)$, que la política migratoria, en los países más desarrollados, está reñida con otras estructuras de primer orden en el sistema internacional. Mientras se pretenden blindar las fronteras para impedir la entrada de inmigrantes y refugiados, se propone crear espacios económicos sin fronteras. Parece que por una parte discurren los flujos de capital y de información, y por otra los movimientos de personas, la inmigración.

No obstante, se entiende en cualquier caso, tal y como recoge Miraut (2004, 343-344), los recelos que suscita el fenómeno inmigratorio, en los habitantes de las zonas geográficas que sufren ese fenómeno de superpoblación. Pero la solución del problema no radica precisamente en la eliminación del fenómeno en cuestión, sino en el mejor tratamiento del 
mismo. Para ello, es necesario poner en marcha políticas públicas efectivas de redistribución territorial de la población inmigrante, y también desde luego de la propia población autóctona, estableciendo estímulos apropiados para la instalación en los lugares de menor densidad poblacional.

En muchas ocasiones, las políticas de inmigración asumen como objetivo declarado explícitamente la necesidad de preservar los fundamentos básicos de la civilización propia. Y ello se hace, bien porque se entiende que la llegada de los inmigrantes al territorio del que se trate puede perjudicar el mantenimiento de las señas de identidad de la población autóctona o bien, porque las costumbres que traen consigo los inmigrantes pueden resultar indigeribles, en buena medida, a los miembros de la sociedad de acogida (Miraut, 2004, 344).

El planteamiento del problema en estos términos resulta, no obstante, inaceptable porque antepone la idea de la identidad colectiva a los requerimientos que impone la idea de identidad individual, obviando el hecho cierto que supone el imparable fenómeno de la intercomunicación cultural que caracteriza a nuestro tiempo. Como bien se ha dicho "Pretender detener el proceso de las identidades colectivas es como pretender detener el paso del tiempo, un esfuerzo inútil. Por otra parte, el perpetuarse un determinado modo de ser homogéneo en una base territorial concreta, no puede ser tampoco un motivo para oponerse a que los demás puedan tener el acceso mínimo a los derechos que exige el respeto a su dignidad personal. La identidad colectiva no puede suponer un freno para los derechos debidos a cada individuo" (Miraut, 2004, 344).

Por otro lado, parece también evidente que la idea de identidad es una idea ambigua que no entra precisamente en crisis por el advenimiento del fenómeno inmigratorio. Su crisis obedece a razones mucho más complejas entre las que destacan las de índole específicamente económica y mercantil. Así, Rey Pérez $(2006,281)$ resalta esta idea señalando que "El Estado quiere presentarse como salvaguarda de la identidad. Una identidad que se ve amenazada por el fenómeno de la inmigración. Pero la identidad está en crisis antes o al margen de los movimientos migratorios. El Estado como baluarte de la identidad, se quebró con la crisis de legitimidad que asedió al Estado de bienestar y sus instituciones. Desde entonces, el hueco de la identidad ha sido colmado bien por nacionalismos beligerantes, hoy en expansión, bien por el mercado, que ofrece identidades volátiles a ritmo de la moda. El Estado quiere hacerse necesario como garante de la identidad, sin darse cuenta que ésta se encuentra amenazada por el mercado y no por la inmigración, que, en todo caso, lo que podría hacer es enriquecer el proceso de construcción de identidades". 
La segunda razón cultural alegada, el rechazo a las costumbres y prácticas culturales que pudieran llevar a cabo los inmigrantes, carece también de fundamento desde la perspectiva de la realización de los derechos del inmigrante. Ante todo, porque si lo que de verdad preocupa a los miembros de la sociedad de acogida es que esas prácticas se lleven a cabo, resultaría indiferente que las mismas se realizaran en la sociedad de acogida o se llevaran a cabo fuera de ellas. El hecho material que supone la realización de la práctica cultural es idéntico con independencia del lugar concreto en el que tales prácticas se produzcan. Y si lo que preocupa a la sociedad de acogida es ese hecho, parece absurdo esgrimirlo como un motivo para el rechazo a la inmigración. Como bien se ha dicho, "es absurdo y cínico pensar que lo que no vemos no existe si tenemos la certeza de su existencia, y esa certeza está clara desde el momento en que sirve de base para las posturas de rechazo a la inmigración" (Miraut, 2004, 345).

Se podría ciertamente esgrimir que lo que le preocupa a la población de la sociedad de acogida no es tanto la realización de la conducta en cuestión como el riesgo de contagio que la misma puede provocar en la población autóctona. Es, no obstante éste, un argumento muy débil porque vendría a poner de manifiesto una preocupante falta de solidez de los fundamentos culturales de la población autóctona, que quedaría en evidencia ante el riesgo de su disolución al entrar en contacto con otros fundamentos culturales diferentes (Miraut, 2004, 346). Habría que pensar, muy al contrario, que el contraste de sus propios fundamentos culturales con otras culturas diferentes proporciona al individuo una ocasión inmejorable para desarrollar de la manera más libre su personalidad, asumiendo, tras su correspondiente evaluación personal, los aspectos positivos que pudiera encontrar en los diversos modelos culturales que se le presentan.

Las políticas de inmigración asumen generalmente, el punto de vista de la sociedad de acogida. Son los intereses de sus integrantes los que en última instancia se tratan de preservar y guían normalmente el contenido de las acciones públicas que se emprenden. Se explica así que se esgrima sin mayor reparo la necesidad de preservar la seguridad personal, el nivel de vida alcanzado o los fundamentos básicos de la civilización propia frente al riesgo que puede generar la llegada de los inmigrantes y su instalación en la sociedad receptora.

En recientes publicaciones del Observatorio Permanente de Inmigración del Ministerio de Empleo y Seguridad Social, se plasma la idea de que "vinculado a la ausencia de una estrategia de integración coherente por parte de los gobiernos de las sociedades receptoras, se encuentran con otra premisa ausente en los modelos de integración: la incorporación de las 
personas inmigrantes se produce en el marco de un amplio abanico de normas e instituciones diseñadas inicialmente con finalidades ajenas al hecho inmigratorio"(Godenau et al, 2014, 24), ratificando el indicativo base presupuesto del presente trabajo, sobre que la visión de la inmigración ha de ir evolucionando para llegar a tener una lectura en términos de derechos de igualdad y participación

En el fondo, la asunción de estos objetivos declarados provoca elevados rendimientos electorales a quienes los proponen, porque son sobre todo los beneficiados por esas políticas de inmigración quienes van a determinar la formación de los órganos de representación del país. En estos casos la adopción del punto de vista de los intereses de la sociedad de acogida deja al descubierto la situación de absoluto desamparo en que se encuentra el inmigrante, cuya consideración por parte de los poderes públicos viene, a la hora de la verdad, determinada por razones por completo ajenas a su propia condición personal y a los derechos que le son inherentes.

Nos encontramos, no obstante, en este tipo de supuesto ante una situación más o menos explícitamente declarada, asumida directamente por los actores de las políticas públicas. Es una situación que, precisamente por su carácter declarado, resulta fácilmente susceptible de una consideración crítica. El problema se agrava cuando nos encontramos ante un principio guía de las políticas de inmigración no declarado que sin embargo, se encuentra latente en el ambiente. No cabe duda, en este sentido, de que las actitudes paternalistas que adopta en muchas ocasiones el Estado, proporcionando a los inmigrantes una cierta satisfacción a las exigencias que imponen determinados derechos fundamentales, obedecen en mayor medida al intento de preservar la conciencia personal propia de los integrantes de sus órganos representativos con respecto a la denigrante situación en que aquellos se encuentran.

En el juicio crítico sobre las políticas públicas de inmigración habrá de tener en cuenta a este respecto que, desde perspectivas diferentes y con enfatizaciones diversas, son sobre todo los intereses de la población autóctona y no la realización de los intereses de la población inmigrante, los que determinan a la hora de la verdad su sentido y orientación. Una orientación que pone desde luego en cuestión, en muchas ocasiones, la pretendida vigencia efectiva del principio de universalidad de los derechos humanos. En esa situación, las enfáticas declaraciones de los derechos como derechos del hombre, derechos universales por consiguiente, se presentan como un auténtica irrealidad, al estar desconectada por completo de los presupuestos de hecho de la vida cotidiana. Pero es que además, lo más grave es que pretender encontrar razones para justificar desde la propia óptica de los derechos humanos una 
situación que contradice los principios fundamentales de su filosofía. Es lo que viene a resaltar De Lucas $(2006,66)$ cuando señala que "el problema real es que a los inmigrantes no se les reconocen derechos que se formulan como universales, y es un problema porque no se trata de una cuestión de hecho, sino de un régimen jurídico que pretende estar justificado, que encuentra razones para tal discriminación".

Resulta curioso, por otro lado, que olviden los miembros de la sociedad receptora el sentido real que habría que tener un planteamiento inteligente de la defensa de sus propios intereses, no ya de los intereses de la población inmigrante, en relación al problema que plantea en nuestros días el fenómeno inmigratorio. Luigi Ferrajoli $(2005,176)$ ha advertido con meridiana claridad acerca del riesgo en el que, de manera tan irresponsable, están incurriendo a este respecto las sociedades receptoras del fenómeno inmigratorio.

Se pronuncia en estos términos cuando defiende que "la óptica realista debería, por tanto, invertirse: lo que aquí aparece como irreal en el corto plazo, esto es, el cumplimiento efectivo de los deberes de cooperación correlativos a los derechos humanos sancionados por el derecho internacional es, a largo plazo, la única alternativa realista, como advierte el propio preámbulo de la declaración Universal de los Derechos del Hombre, a un futuro de guerras, de violencia y terrorismo" (Ferrajoli, 2005, 176-177)

Y establece la idea de que "no hay nada más políticamente irreal que la ilusión de que la realidad pueda permanecer como está, sin que se vea amenazado nuestro despreocupado tren de vida y sin que resulten desacreditadas las propias fuentes de legitimación de nuestras ricas democracias"(Ferrajoli, 2005, 176-177).

Es evidente, que el inmigrante mejora de hecho sensiblemente su situación personal con la acción asistencial del Estado. Pero ello, no puede tampoco hacer perder de vista el hecho de que esa acción asistencial obedece, en mayor medida, al sentimiento de necesidad de evitar situaciones de mala conciencia que experimentan los miembros de la sociedad de acogida. Para decirlo en palabras De Lucas $(2001,45)$, la sociedad "adopta el disfraz humanitario, de tan buenos rendimientos electorales, de quien está dispuesto a solucionar el problema de los que están aquí". Pero los miembros originarios de la sociedad receptora se olvidan de que la inmigración representa un fenómeno mucho más complejo, del que los que están aquí no constituyen más que una mera proyección. Una proyección que ciertamente habría que atender de la manera más adecuada, y desde luego, sin el cicaterismo que adoptan normalmente las políticas asistenciales del inmigrante, en definitiva proporcionando al inmigrante un tratamiento jurídico y asistencial de persona integral, y no de persona disminuida o devaluada 
paradójicamente por el hecho de constituir la representación puntual de una situación global de injusticia cuya complejidad no se quiere entrar a considerar.

La falta de un compromiso real para atacar el problema en los aspectos más cruciales en que queda en evidencia la dignidad de la persona deja al descubierto la motivación última de las políticas públicas de inmigración. Así puede decirse que, aun en los casos en que pueda resultar favorecido, en alguna medida que no es nunca la deseable por el inmigrante, la activación de las políticas de inmigración atiende sobre todo a los intereses de la población autóctona. Intereses que en los casos de la preservación de la seguridad personal, del nivel de vida alcanzado y de los fundamentos básicos de la civilización propia, tienen un carácter prioritariamente material y, por el contrario, en el caso de la preservación de la conciencia personal con respecto a la situación de los demás, un carácter prioritariamente espiritual. Pero ese carácter espiritual no le hace menos real, ni tampoco desde luego menos necesitado de atención.

\section{CONCLUSIONES}

El mantenimiento de la autonomía base de las culturas de los países de acogida, puede identificarse con la necesaria restricción o limitación de los derechos y libertades de los inmigrantes. Las políticas públicas en materia de inmigración no consiguen una respuesta sencilla a esa identificación.

En este sentido, se defiende que la responsabilidad de los Estados en política inmigratoria, les obliga a intentar asumir criterios de cohesión social en clave de identidad cultural, siguiendo como máxima el ideario de los contenidos reconocidos por los derechos humanos.

Una auténtica integración de los inmigrantes exige un esfuerzo común de todos los agentes implicados, así como también de la población autóctona, para que se pueda materializar esa bidireccionalidad que propicia la integración.

Las medidas articuladas dentro de políticas de integración en el ámbito del Estado acogente debe adquirir un carácter transversal que permita el acceso de los inmigrantes a un mayor nivel de derechos ciudadanos.

Las medidas articuladas dentro de las políticas de integración, se han de centrar en facilitar el reconocimiento de derechos y deberes de la población inmigrante como punto de partida, o al menos mínimamente diferenciada que permita progresivamente, la adquisición de 
un estatuto jurídico completo a los inmigrantes como base argumental suficiente del reconocimiento de la dignidad de todo ser humano.

\section{REFERENCIAS BIBLIOGRÁFICAS}

BALAGUER CALLEJÓN, F., "El Estado Social y democrático de derecho. Significado, alcance y vinculación de la cláusula del Estado Social", AA.VV. J.L. Monedero Pérez, C. Molina Navarrete y M.N. Moreno Vida (dirs.), Comentario a la Constitución socioeconómica de España, Granada: Comares, p.89, 2002.

BAUMAN, Z., La sociedad individualizada, Cátedra, Madrid, p.161,2001.

CALVO GARCÍA, M., GASCÓN SORRIBAS, E., Y GRACIA IBÁÑEZ, J., "La inmigración en el ámbito de la administración de justicia", en AA.VV., L. Miraut Martín (ed.), Justicia, Migración y Derecho, Madrid: Dykinson, p.183, 2004.

CARBONELL, M., "La constitucionalización de los derechos indígenas en América Latina: una aproximación teórica", Boletín Mexicano de Derecho Comparado, volumen 36 número 108, México, dic., pp.846-861. (13), 2003.

DE ASÍS ROIG, R., "Algunas reflexiones sobre el fenómeno migratorio y los derechos humanos", en AA.VV.,V. Zapatero Gómez (ed.), Horizontes de la filosofía del derecho. Homenaje a Luis García San Miguel, Tomo I, Madrid: Universidad de Alcalá, p.544, 2002.

DE LUCAS MARTÍN, J., "Algunas tesis sobre el desafío que plantean los actuales flujos migratorios a la universalidad de los derechos humanos", en AA.VV., I. Campoy Cervera, Una discusión sobre la universalidad de los derechos humanos y la inmigración, Madrid: Dykinson, p.66, 2006.

"Ciudadanía: la jaula de hierro para la integración de los inmigrantes", AA.VV. G. Aubarell y R. Zapata (eds.), Inmigración y procesos de cambio. Europa y el Mediterráneo en el contexto global, Icaria. Antrazyt, lemed, Barcelona, pp. 215-236, 2004.

"Cómo introducir el principio de justicia en las políticas de inmigración", en AA.VV., L. Miraut Martín (ed.), Justicia, Migración y Derecho, , Madrid: Dykinson, p.42, 2004. Globalización e Identidades. Claves políticas y jurídicas, Barcelona: Icaria, p.52, 2003.

"Algunas propuestas para comenzar a hablar en serio de política de inmigración", en AA.VV., J. de Lucas y F. Torres (eds.), Inmigrantes: ¿cómo los tenemos?. Algunos desafíos y (malas) respuestas, Madrid: Talassa, p.30, 2002.

"Las condiciones de un pacto social sobre la inmigración", en AA.VV., N. Fernández Sola y M. Calvo García (coords.), Inmigración y derechos, Zaragoza: Mira Editores, p. 45, 2001.

"Las propuestas sobre políticas de inmigración en Europa y la nueva ley 4/2000 en España", en AA.VV., A. Colomer Viadel (coord.), Emigrantes y estabilidad en el mediterráneo. La polémica Ley de Extranjería, Valencia: Nomos, p. 141, 2001.

DEL REAL ALCALÁ, J.A., "Problemas de gestión de la diversidad cultural en un mundo plural", en Derechos Fundamentales, Valores y Multiculturalismo, Madrid: Dykinson, p.177, 2005. 
FERRAJOLI, L., "Los derechos fundamentales en la teoría del derecho", "en G. Pisarello (ed.), Los fundamentos de los derechos fundamentales, Madrid: Trotta, pp. 176-177, 2005. "El derecho como sistema de garantías", en L. Ferrajoli, Derechos y garantías. La ley del más débil, (traducción de Andrés Ibáñez, P. y Greppi, A.), Madrid: Trotta, p. 32, 2001.

"Los fundamentos de los derechos fundamentales", en L. Ferrajoli, Los fundamentos de los derechos fundamentales, De Cabo, A. y Pisarello G., (eds.), (traducción de Perfecto Andrés, Antonio de Cabo, Miguel Carbonell, Lorenzo Córdova, Marcos Criado y Gerardo Pisarello), Madrid: Trotta, pp. 337 y 369, 2001.

GARCÍA AMADO, J.A., "¿Por qué no tienen los inmigrantes los mismos derechos que los nacionales?", en AA.VV., L. Miraut Martín (ed.), Justicia, Migración y Derecho, Madrid Dykinson, p. 242, 2004.

GODENAU, D., RINKEN, S., et al, La integración de los inmigrantes en España: una propuesta de medición a escala regional, Madrid: Ministerio de Empleo y Seguridad Social, p. 24. 2014.

GÓMEZ CIRIANO, E.J., “¿Excluyendo desde la integración? Un análisis del modelo de integración activa", Revista Documentación Social , número 159, pp.85-101, 2010.

MIRAUT MARTíN, L., "Los objetivos de las políticas de inmigración", en AA.VV., L. Miraut Martín (ed.), Justicia, Migración y Derecho, Madrid: Dykinson, pp. 333-345, 2004.

PECES-BARBA MARTíneZ, G., LLAMAS CASCÓN, A., FERNÁNDEZ LIESA, C., Textos básicos de Derechos Humanos, Thomson Aranzadi, Navarra, pp.29 y ss., 2001.

PÉREZ DE LA FUENTE, O., "Inclusión, redistribución y reconocimiento: algunas paradojas sobre los inmigrantes", en AA.VV., I. Campoy Cervera (ed.), Una discusión sobre la universalidad de los derechos humanos y la inmigración, , Madrid: Dykinson, p. 256, 2006.

REY PÉREZ, J.L., "Identidad e inmigración o la lucha contra la inmigración como actividad estatal de supervivencia", en AA.VV., Una discusión sobre la universalidad de los derechos humanos y la inmigración, I. Campoy Cervera (ed.), Madrid: Dykinson, p. 281, 2006.

RUIZ RUIZ, R., "Liberalismo y comunitarismo: dos perspectivas antagónicas del fenómeno multicultural", en Derechos Fundamentales, Valores y Multiculturalismo, Madrid: Dykinson, pp.41 y 57-58, 2005.

SASSEN, S., ¿Perdiendo el control?. La soberanía en la era de la globalización, Barcelona: Bellaterra, p. 95, 2001.

SECO MARTÍNEZ, J.M., RODRÍGUEZ PUERTO, R., "Espacios y ritmos para una nueva concepción de la ciudadanía", en AA.VV., A. de Julios Campuzano (ed.), Ciudadanía y derecho en la era de la globalización, Madrid: Dykinson, p. 330, 2007.

SOLANES CORELLA, A., "Integración sin derechos: de la irregularidad a la participación", Cuadernos electrónicos de filosofía del derecho, número 14, pp. 1-2, 2006.

"La situación jurídica del extranjero irregular en España”, en AA.VV., N. Fernández Sola y

M. Calvo García (coords.), Inmigración y derechos, Zaragoza: Mira Editores, p. 238, 2001. 
SOUTO GALVÁN, B., Inmigración y mediación intercultural: aspectos jurídicos, Madrid: Dykinson, p. 9, 2014.

THIEBAUT, C., Vindicación del ciudadano, Barcelona: Paidós, p. 24, 1998.

VAN DIJK, T.A., Dominación étnica y racismo discursivo en España y América Latina (traducción de Montse Basté), Barcelona: Gedisa, p. 52, 2009.

WINCKLER, S., "Inmigración y exclusión: las personas desplazadas en la Comunidad Europea", en AA.VV., N. Belloso Martín (coord.), Para que algo cambie en la teoría del derecho, Burgos: Universidad de Burgos, Burgos, p. 156, 1999.

Trabalho enviado em 04 de maio de 2017.

Aceito em 18 de junho de 2017. 